\title{
Por uma reforma agrária aquática? Luta por reconhecimento social dos ribeirinhos do rio tapajós para a construção de Acordos de Pesca
}

\section{For an aquatic agrarian reform? Struggle for social recognition of the Tapajós riverside's communities for the construction of Fisheries Agreements}

Rubens Elias da Silva ${ }^{1}$

Artigo recebido em: 20 de novembro de 2017. Artigo aprovado em: 10 de dezembro de 2017.

\begin{abstract}
Resumo: A mobilização política das comunidades ribeirinhas da FLONA do Tapajós e da RESEX Tapajós - Arapiuns em busca da regulamentação do acesso e uso dos recursos pesqueiros do rio por meio de acordos de pesca é compreendida, neste artigo, através das categorias analíticas como territórios socioambientais e reconhecimento social. O manejo comunitário dos territórios aquáticos pode possibilitar a esses atores sociais a conquista do reconhecimento de seus direitos, ao dividir o território segundo critérios sociais em busca da promoção da qualidade de vida num processo entendido como reforma agrária aquática.

Palavras-chave: comunidades ribeirinhas, acordos de pesca, reconhecimento social.
\end{abstract}

Abstract: The political mobilization of Tapajós riversides communities from FLONA and the RESEX Tapajós - Arapiuns in order to regulate the access and use of the fishing resources through fisheries agreements is understood in this article in a analytical categories way, such as social and environmental territories and social recognition. The community management of aquatic territories can enable these social actors to gain recognition of their rights by dividing the territory according to social criteria in order to promote the quality of life in a process understood as aquatic agrarian reform.

Key Words: riverside communities, fisheries agreements, social recognition..

\section{Introdução}

Este artigo tem como intuito debater acerca da mobilização política das comunidades ribeirinhas localizadas dentro da jurisdição da Floresta Nacional do Tapajós e Reserva Extrativista do Arapiuns para a construção de uma legislação específica para regulamentar o uso, acesso e usufruto dos recursos pesqueiros existentes nas águas

\footnotetext{
${ }^{1}$ Doutor em Sociologia (PPGS / UFPB). Professor Adjunto II do Centro de Formação Interdisciplinar da Universidade Federal do Oeste do Pará e dos Programas de Pós Graduação do PPGCS e PPGSAQ nesta mesma IES. E-mail: hellazer09@gmail.com
} 
do rio Tapajós. Para compreendermos esse processo social e político dos ribeirinhos, os conceitos de reconhecimento social em Honneth (2011) e territórios socioambientais, preconizados por Esterci (2014), são fundamentais para o entendimento das dinâmicas sociais e culturais no agenciamento dos atores envolvidos e a construção coletiva da ideia de territórios aquáticos destinados ao manejo de recursos pesqueiros. As relações recíprocas entre engajamentos dos ribeirinhos para assumirem seu modo de vida como base e fundamento para a reprodução da vida material e cultural perpassam, no caso aqui analisado, no enfrentamento da questão do território como eixo central onde a produção dos meios necessários à vida. Sendo assim, o território é o espaço sobreo qual determinado grupo social garante a seus membros direitos estáveis de acesso, uso e controle sobre seus recursos naturais (CASTRO, 2000; ALMEIDA, 2010). E é no território que determinadas culturas, através da transformação contínua da natureza e da trajetória histórica e ecológica dessa coletividade, cujas formas materiais e imateriais de percepção e representação do mundo natural são estabelecidas, transcendendo o aspecto meramente econômico (GODELIER, 1981). É com a ambientalização das lutas sociais nas últimas décadas (ACSELRAD, 2010) e a emergência dos discursos pautados no desenvolvimento sustentável e modelos alternativos de gestão do território sob a gestão de grupos étnicos que o conceito de território socioambiental faz sentido e alcança a pauta política de comunidades tradicionais em graves contextos de injustiça social e privação de direitos (MENEZES, 2010). Os territórios socioambientais compreendem espaços inovadores de produção de conhecimento e de formulação de projetos políticos e ambientais, garantindo a reprodução social de povos tradicionais aí existentes (Esterci, Ibidem). Sendo assim, podemos pensar o movimento popular das comunidades ribeirinhas do Tapajós - lideranças locais, regionais, atores coletivos e gestores de órgãos do Governo e ONGs - como protagonista desse processo anteriormente descrito, mas contextualizado a partir de demandas sociais, econômicas e ecológicas locais.

Os conflitos socioambientais no âmbito da pesca ocorrem na Amazônia desde os anos 70 (MCGRATH et al.,1998; PERROTA, 2014). Autores como Esterci (Ibidem) e McGrath et al (1991) afirmam que a política de modernização tecnológica da pesca no período que levou à intensificação da pressão sobre as áreas de pesca, ocasionara conflitos entre inúmeros atores sociais. A região de várzea santarena foi extensamente 
estudada a respeito dessas intensas disputas e conflitos oriundos de diferentes atores sociais competindo pelo uso dos recursos pesqueiros dos lagos (McGRATH et al., Ibidem). Acresce-se a isso, a peculiaridade de que nessa região santarena foram construídos os primeiros regulamentos comunitários a respeito do uso, acesso e usufruto dos recursos pesqueiros localizados nos lagos comunitários que, comumente, são denominados de "acordos de pesca". Os primeiros acordos de pesca datam dos anos setenta, tendo a Ilha de São Miguel - região do Aritapera - o protagonismo na construção dos primeiros acordos e de sua efetividade ao longo de décadas (FERREIRA, 2014; OVIEDO et al., 2015). As regiões de várzea, em Santarém, banhadas pelos inúmeros intercursos do rio Amazonas, dadas as suas especificidades topológicas e hidrográficas, conseguiram organizar-se tanto politicamente quanto encontraram legitimidade institucional - via Colônia de Pescadores local e órgãos públicos como o Instituto Brasileiro do Meio Ambiente e dos Recursos Naturais Renováveis (IBAMA) e o Instituto Chico Mendes de Conservação da Biodiversidade (IcmBio) - para o respeito às regras sociais referendadas nos documentos aprovados - os acordos de pesca - coletivamente em reuniões em cada comunidade interessada pela regulamentação do acesso ao território pesqueiro local de modo a impedir o acesso de embarcações estranhas à comunidade e excluída do processo de construção dos referidos acordos.

No entanto, as comunidades ribeirinhas do rio Tapajós, de ambas as margens e mantidas sob a legislação arbitrada pelo Sistema Nacional de Unidades de Conservação (SNUC), ficaram ao longo dessas décadas, à parte desse processo social de politização dos atores sociais no que tange à regulamentação dos territórios comunitários destinados à pesca artesanal e fundamental para a reprodução social das comunidades e na promoção da qualidade de vida local. De acordo com as falas dos comunitários da FLONA, por exemplo, apenas os lagos e igarapés locais eram acobertados pela Lei 9.985/2000 do SNUC; entretanto, grande parte dos recursos pesqueiros destinados, quase que exclusivamente, para a alimentação familiar, eram oriundas das águas do rio Tapajós. Eis aí o cerne do conflito que as inúmeras comunidades ribeirinhas depararam-se ao longo de décadas: a constante presença de grandes barcos motorizados nas águas do rio e com tecnologia de impacto extenso nos estoques pesqueiros, capturando o pescado de 
forma indiscriminada. Como as águas do rio eram consideradas res nullius ${ }^{2}$, os órgãos institucionais do Governo não tinham instrumentos legais para apreender apetrechos de pesca, embarcações, além, obviamente, do número reduzido de funcionários públicos para efetuar uma pretensa "fiscalização" do extenso rio - o Tapajós tem cerca de $19 \mathrm{~km}$ de largura, em certos trechos. Sem dúvida, esse cenário social de constante perda dos recursos pesqueiros para pescadores embarcados de outros centros regionais fez com que as comunidades, nos últimos anos, passassem a se mobilizar para proteger não somente os recursos pesqueiros que elas consideram de/para uso legítimo dos comunitários, mas lutar pelo reconhecimento social de sua luta para a construção de uma identidade ribeirinha amparada pelo uso de acordos de pesca arbitrados e protegidos pelo Estado.

Como já foi defendida em trabalho anterior, pensamos que a extensionalidade dos acordos de pesca em uso nas diversas regiões de Santarém e a historicidade da mobilização política dos ribeirinhos visando proteger a manutenção dos estoques pesqueiros e a garantia da proteína na dieta alimentar ao longo das gerações pode ser compreendida como um processo de reforma agrária aquática (SILVA e FERREIRA, mimeo). Este artigo é resultado da pesquisa de Iniciação Científica com a participação de um bolsista pela Universidade Federal do Oeste do Pará e graduando em Antropologia. O projeto de pesquisa de iniciação científica intitulado "Gestão social das águas na FLONA do Tapajós e Reserva Extrativista do Tapajós-Arapiuns: estudo socioantropológico sobre os conflitos para demarcação de zonas de pesca e mobilização social para a gestão e preservação dos territórios de pesca comunitária" cuja proposta foi compreender a organização social do espaço de exploração dos recursos aquáticos, enquanto gestão do território para usufruto comum na Flona do Tapajós e Reserva Extrativista do Tapajós-Arapiuns. Foi utilizada a metodologia qualitativa amparada na observação participante e aplicação de questionários semi-estruturados de modo a detectar questões-chave para a construção do relato etnográfico. As entrevistas serão norteadas tomando como base o diálogo, no sentido de construir laços de confiança entre pesquisador (es) e interlocutores, de modo que apreenda os relatos e os dados históricos e institucionais, elementos fundamentais

\footnotetext{
${ }^{2}$ Res nullius é uma expressão latina, composta de res + nullius, significando literalmente "coisa sem dono" ou "coisa de ninguém".
} 
para a análise do social (ESPINHEIRA, 2008), compreendida aqui como a observância das transformações no campo da construção da intersubjetividade - arena de significados e sentidos em torno de um imperativo moral e ético na seara das normas costumeiras e institucionalizadas por meios de portarias, instruções normativas - nessas comunidades tradicionais locais.

\section{Os LOCII do debate em questão}

A Floresta Nacional do Tapajós foi criada através do Decreto $n^{\circ} 73.684$, de fevereiro de 1974 e Lei $n^{\circ} 12.678$ de 25 de junho de 2012 e envolveu intensos conflitos entre moradores da região e os órgãos estatais responsáveis pela preservação e conservação do espaço natural. Essa Unidade de Conservação tem uma área de 549.066,87 hectares, localiza-se nos municípios de Placas (PA), Rurópolis (PA), Belterra (PA), Aveiro (PA), oeste do Pará. Soares (2004) afirma que, quando da criação da Flona do Tapajós, o antigo IBDF (Instituto Brasileiro de Desenvolvimento Florestal) não verificou detalhadamente a existência de população residente ou a situação fundiária na área definida como Floresta Nacional. As comunidades locais precisaram se articular politicamente para permanecer nesse território, uma vez que as práticas conservacionistas desrespeitam os direitos civis das populações diretamente envolvidas e ignoram o vasto conhecimento e práticas de manejo da floresta que essas culturas detêm (DIEGUES, 2000). É uma unidade de uso sustentável, desde que garantida sua conservação, abrigando diversos tipos de florestas, tais quais: 1) floresta tropical densa com árvores emergentes e relevo plano; 2) floresta tropical densa com árvores emergentes e relevo dissecado em colinas e ravinas; 3) floresta tropical fluvial (parte do ano inundada); 4) floresta tropical aberta com palmeiras e cipós e relevo plano; 5) floresta tropical aberta com palmeiras e cipós e relevo dissecado em colinas e ravinas; 6) florestas secundárias, principalmente ao longo de suas fronteiras e vias de acesso (capoeiras) (SOARES, 2004).

Segundo o Relatório Parametrizado do Ministério do Meio Ambiente, a Flona do Tapajós tem como objetivo uso múltiplo sustentável dos recursos florestais e a pesquisa científica, com ênfase em métodos para exploração sustentável de florestas nativas. A Unidade faz limite a oeste com o Rio Tapajós, um dos dez principais rios da região Amazônica em termos de área de drenagem, estimada em 490 mil km2 e com vazão 
Revista Ciencias da Sociedade (RCS), Vol. 1, n. 2, p.81-102, Ju/Dez 2017

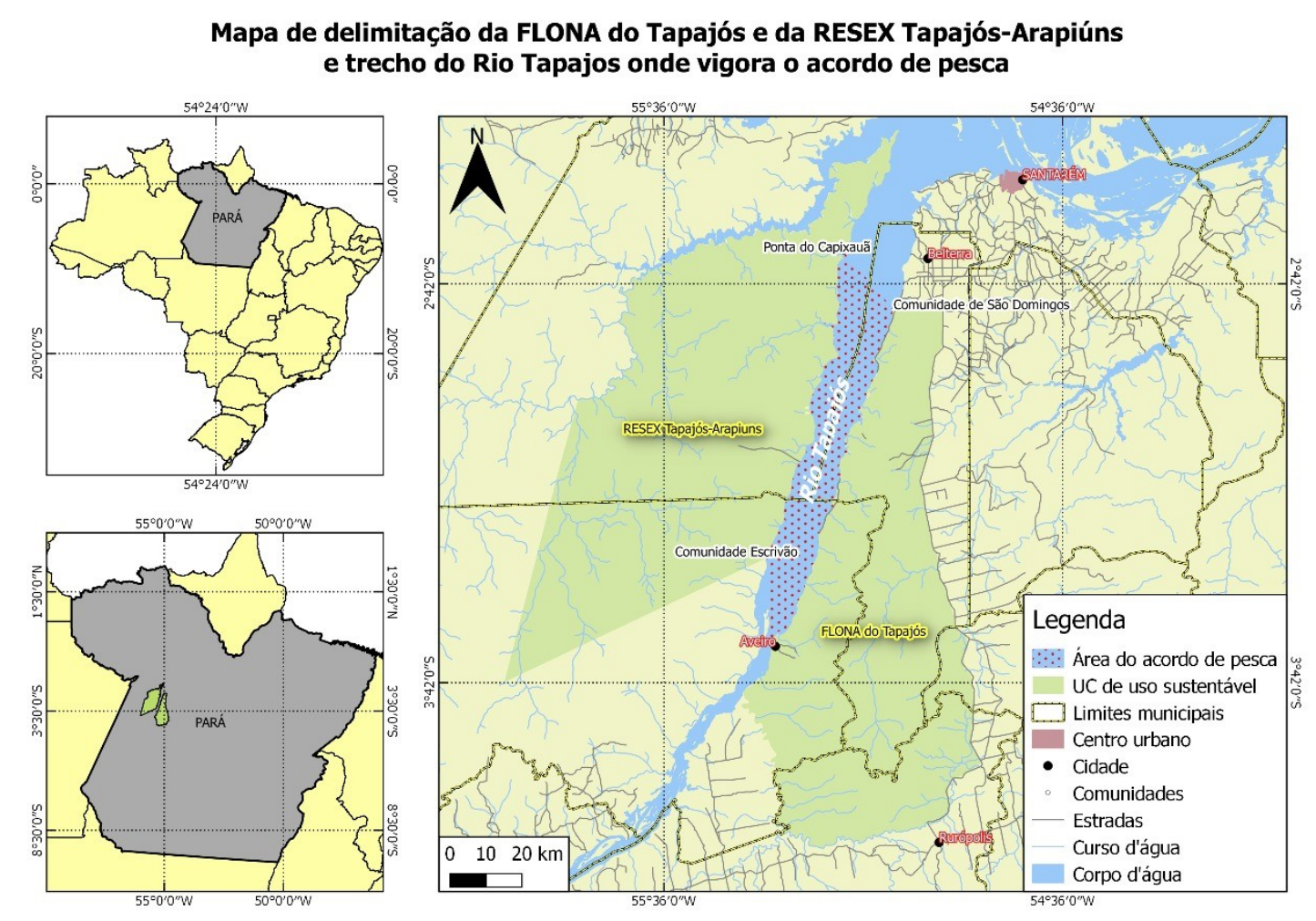

Figura 1. Autoria do mapa: Rodolfo Maduro Almeida (2017).

de 1,35 mil m3/segundo. Na foz do Rio Arapiuns, o Rio Tapajós apresenta mais de 40 $\mathrm{km}$ de largura. É um rio de águas claras, navegável ao longo de $345 \mathrm{~km}$ por barcos de calado de até 1,5 m. Ao sul faz limites com o Rio Cupari, tributário do Rio Tapajós. Internamente, a Flona apresenta uma rede hidrográfica dividida entre as calhas do Rio Tapajós a oeste e a bacia do Rio Curuá-Una a leste. Na região de declive encontra-se a nascente do Rio Moju, tributário do Curuá-Una, cuja foz é no rio Amazonas. Tem uma população local de 22.800 moradores.

A Reserva Extrativista Tapajós - Arapiuns, localizada no município de Santarém, tem uma área total de 677.513,24 hectares e foi criada pelo Decreto $s / n^{\circ}$ de 06 de novembro de 1998. Segundo dados do Ministério do Meio Ambiente, a Reserva Extrativista Tapajós - Arapiuns é uma área utilizada por populações extrativistas tradicionais, cuja subsistência baseia-se no extrativismo e, complementarmente, na agricultura de subsistência e na criação de animais de pequeno porte, e tem como objetivos básicos proteger os meios de vida e a cultura dessas populações, e assegurar o uso sustentável dos recursos naturais da unidade. Ainda segundo esse documento, a tipologia vegetal 




Figura 2. Comunidade de Marituba, Flona do Tapajós.

predominante na RESEX é de Floresta Ombrófila Densa, que ocorre em $88 \%$ da área total da Unidade cobrindo aproximadamente 591.420,00 hectares. Esta fitofisionomia é caracterizada por árvores de grande porte, presença de lianas lenhosas e epífitas em abundância. Suas características ecológicas principais são as elevadas temperaturas (médias de $25^{\circ} \mathrm{C}$ ) e alta precipitação, bem distribuída durante o ano (de 0 a 60 dias secos), o que determina uma situação bioecológica praticamente sem período seco. Tem um total de 3.874 moradores distribuídos em diversas comunidades.

\section{Conflito e mobilização política para a construção de territórios socioambientais}

Para contextualizarmos as dinâmicas sociais dos conflitos nessa região que compreende os municípios de Santarém, Belterra e Aveiro, na região oeste do Estado do Pará, é necessária a descrição de fatos relacionados à articulação das lideranças locais através de instituições públicas federais, quais sejam o IcmBio e Universidade Federal do Oeste do Pará. No dia 6 de outubro de 2015 foi acertada a viagem para a comunidade de Marituba, quilômetro 86 da rodovia Santarém-Cuiabá, dentro da jurisdição da 


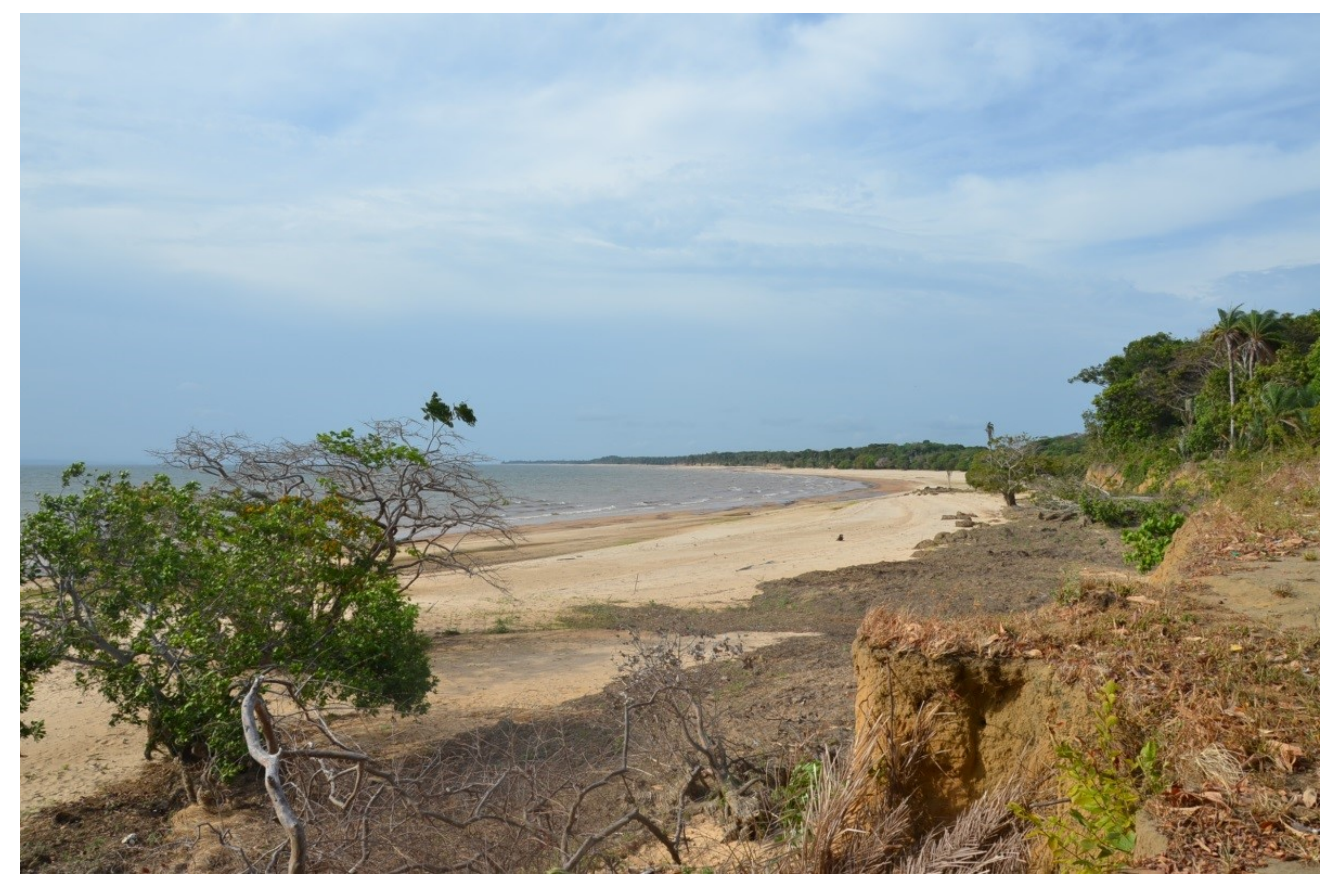

Figura 3. Rio Tapajós. Comunidade de Vila Franca, localizada na RESEX TapajósArapiuns. Arquivo pessoal.

Floresta Nacional do Tapajós. Saímos de Santarém, no dia 08 de outubro, às 6 h30 da manhã, num total de 5 indivíduos, apenas eu e meu bolsista representando a UFOPA. Nesse dia, em Marituba, ocorreu a 54ª Reunião Ordinária do Conselho Consultivo da Flona do Tapajós que, uma das pautas, seria o constante conflito entre ribeirinhos da FLONA e barcos-geleiras vindos de fora para capturar pescado em águas consideradas de propriedade comum e de usufruto exclusivo dos moradores tanto da FLONA quanto da RESEX, salvaguardados os limites de cada margem do rio. A reunião iniciou-se às 8:49, com a apresentação das lideranças e, em seguida, a leitura da ata da reunião anterior e a aprovação das disposições dispostas no papel. Reforçou-se a ideia de que é necessário haver uma interconexão entre órgão gestor da floresta e os comunitários de modo a nivelar a qualidade das informações repassadas. Essas reuniões acontecem três vezes ao ano e o Conselho é composto por trinta indivíduos. Esse modelo de gestão das Unidades de Conservação foi instituído através do SNUC (2000), auxiliado por um Conselho Gestor.

Um dos pontos mais tensos da reunião foi a dificuldade de implementação de estratégias de gestão econômica dos recursos naturais nas comunidades de modo que viabilizem a geração de renda, a exemplo do que ocorre em Jamaraquá e Maguari, na 
Flona do Tapajós (SILVA et al. 2016). Nessa dinâmica socioeconômica, as lideranças presentes na reunião ressaltaram que dificuldades - de várias ordens - para trabalhar na roça associam-se ao sistemático desinteresse dos mais jovens a engajar-se à atividade e, para agravar mais o cenário atual, os baixos custos da produção fora da FLONA praticamente desestimula a produção agrícola familiar, pois as mercadorias produzidas localmente tem custo alto e inviabiliza a venda no centro comercial regional, no caso, Santarém (PEREIRA, 2009). Inúmeras dúvidas dos comunitários presentes na reunião a respeito do Crédito de Carbono somaram-se às reclamações referentes à Bolsa Verde ${ }^{3}$. Foi divulgado o Segundo Chamado da Floresta, evento que reúne lideranças de vários Estados amazônicos.

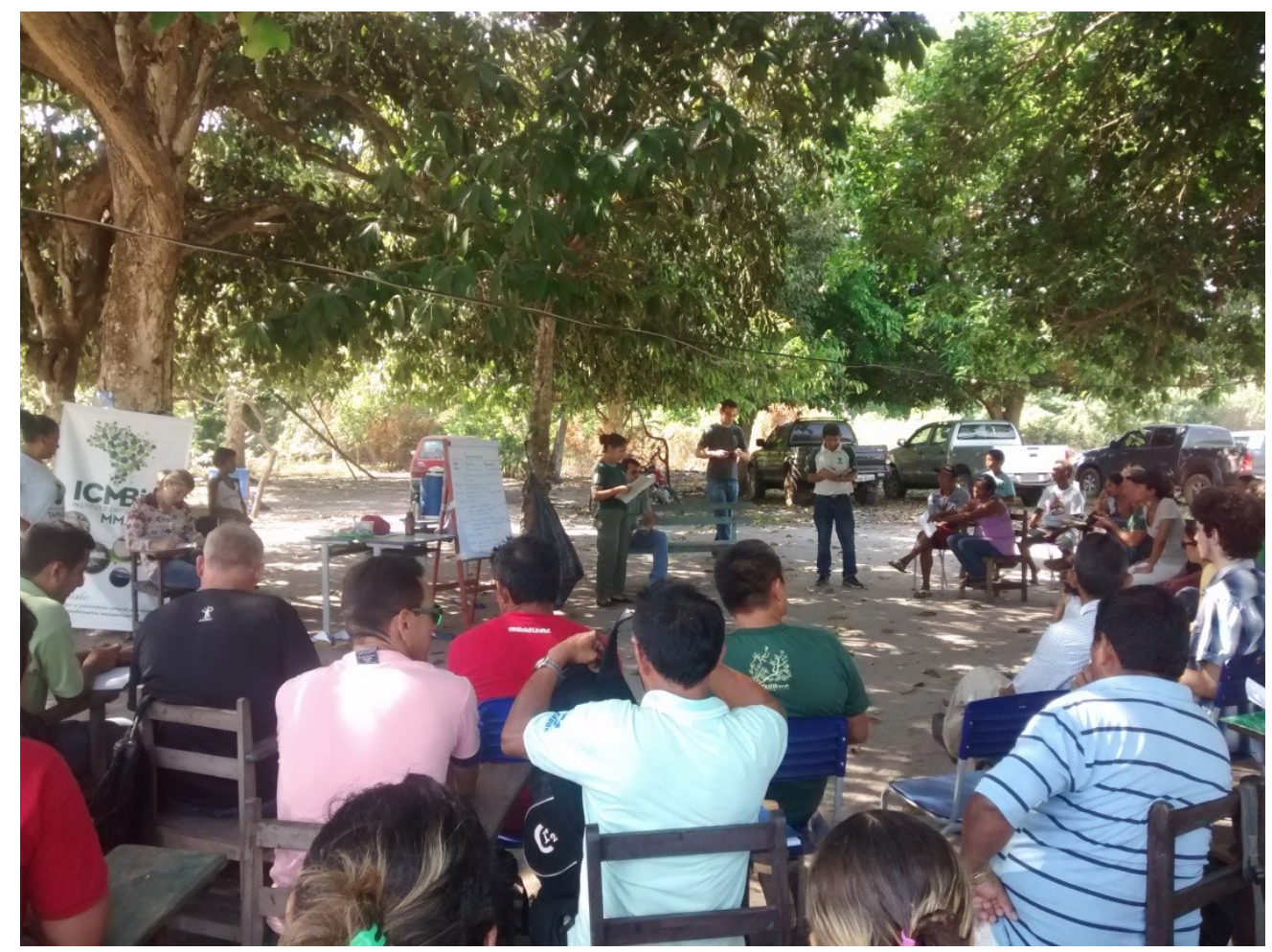

Figura 4. Reunião do Conselho Consultivo da Flona do Tapajós na comunidade Marituba, outubro de 2015.

As lideranças frisaram que vivem exatos trinta anos de conflito de pesca na região do Tapajós e nenhuma solução, até 2015, fora encontrada. Acusam os barcos-geleiras de capturarem os peixes de alto valor comercial, tornando urgente a implantação de um

${ }^{3}$ O Bolsa Verde é um programa de transferência de renda para famílias em situação de extrema pobreza que vivem em áreas de relevância para a conservação ambiental. Funciona como um incentivo às comunidades para que continuem usando, de forma sustentável, os territórios onde vivem (MMA, 2017). Link para acesso: http://www.mma.gov.br/desenvolvimento-rural/bolsa-verde 
plano de manejo associado a uma fiscalização sistemática das águas do rio. Eles acusam essas embarcações de pescarem com malhadeiras, apetrechos de pesca altamente agressivos no mecanismo de captura dos peixes (OVIEDO et al., 2015; McGRATH et al., 1991; (HARTMANN, 2001; McGRATH et al., 1998). Inclusive, acusam os pescadores embarcados de trocarem os peixes de baixo valor comercial - sarda e mapará - por produtos destinados ao consumo, em tabernas das comunidades. Outro fator preocupante, segundo as lideranças, é a passagem das balsas Itaituba - Santarém, que atrapalham não somente a pesca, mas a própria dinâmica migratória dos cardumes. Em outro estudo (SILVA e FERREIRA, mimeo), foi realizado um estudo sistemático dos acordos de pesca implementados nas microrregiões de pesca em Santarém no período de 1990 2004 e, em quase todos os documentos, havia a proibição do uso de malhadeiras nos lagos da várzea, dado seu alto grau de captura de cardumes, pondo em risco a sustentabilidade dos recursos pesqueiros. Presente numa reunião numa comunidade na região do Tapará, testemunhei, numa reunião local, a reivindicação de regras mais rígidas em relação ao tráfego de barcos de viagem próximo às margens da comunidade, pois os comunitários acreditam que a produção de vagas e ondas destroem, silenciosamente, os barrancos e põem em risco as casas localizadas no entorno. Outro problema social e ecológico apontado na reunião do conselho foi a entrada de caravanas nas comunidades da FLONA nos fins de semana com o propósito de usufruir das águas do rio. Bebedeiras, atentado contra a moral local, sujeira na praia e igarapés são motivo de transtorno e conflito dentro das comunidades, a saber, Maguari e Jamaraquá. Outro ponto crítico é o estacionamento de automóveis na areia da praia, destruindo ponto de desova de tracajás assim como o tráfego de jetskis, lanchas, barcos. Todos foram unânimes de que tem de se firmar regras rígidas para esse tipo de conflitualidade.

A pesca em águas interiores é atividade particularmente esquecida e desamparada dentro do contexto regional na Amazônia, a exemplo do que ocorre com os ribeirinhos na região de Santarém (HARTMANN, 2001; OVIEDO et al., 2015). Mesmo assim, eles têm se mobilizado intensamente no sentido de elaborar Acordos de Pesca para gerenciar os recursos pesqueiros de rios e lagos na Amazônia, a exemplo das regiões do Lago Grande, Aritapera e Tapará, em Santarém, Pará. Os conflitos entre ribeirinhos 
locais e os pescadores embarcados nesses barcos-geleiras ${ }^{4}$ são inevitáveis. Segundo eles, há trocas de ameaças e acusações de ambas as partes. Para eles, a pesca comercial e predatória agride não só o modo de vida dos grupos, mas também a biodiversidade presente nos rios amazônicos, a saber, do rio Tapajós. Nesses casos, a ameaça e o conflito têm sido elemento essencial na afirmação de direitos comunitários (DIEGUES, 2001), além da constante construção da mobilização política para o reconhecimento das identidades culturalmente ligadas à atividade pesqueira (MENEZES, 2010; SILVA e SALGADO, 2016) em contextos locais e regionais.

Na perspectiva de análise de Oviedo (2015) e Esterci (2014), a pesca intensiva nas várzeas amazônicas gerou conflitos em duas dimensões complementares, envolvendo atores sociais com intencionalidades distintas e excludentes: a promoção da sustentabilidade dos recursos pensados a partir da visão dos ribeirinhos choca-se em relação aos dos forasteiros que têm acesso ao recurso. Nesse sentido, pensamos que as dinâmicas sociais acima descritas podem ser compreendidas no contexto vivido dos ribeirinhos do Tapajós que esforçam-se para preservar os estoques pesqueiros de modo a garantir a permanência em terras tradicionalmente herdadas e localizadas dentro da legislação do SNUC e gerar proteínas suficientes para a dieta familiar. Daí a necessidade da construção dos acordos de pesca e o consequente manejo dos recursos pesqueiros. Sendo assim, a gestão dos recursos pesqueiros compreende um conjunto de diretrizes estratégicas para administrar os estoques pesqueiros de uma determinada região através da parceria entre atores sociais locais e instituições públicas (RUFFINO, 2005).

De modo geral, os acordos de pesca são um conjunto de regras sociais e, eventualmente jurisdicionadas, estabelecidas por comunidades pesqueiras que definem 0 acesso e o uso do recurso pesqueiro numa determinada região (CASTRO e McGRATH, 2001 apud RUFFINO, 2005). Esses acordos são comunitariamente construídos com o intuito de regulamentar o acesso dos comunitários aos lagos locais e determinam, grosso modo, a quantidade socialmente aceitável de pescado - dependendo do tamanho, ciclo de produção do peixe, o quilo - por pescador / pescadora. Paralelamente a isso, esses acordos instituem quem pode exercer a atividade da pesca no lago e em quais condições.

\footnotetext{
4 Segundo McGrath et al. (1991), os barcos-geleiras, ou simplesmente geleiras, são embarcações armazenadoras de pescado, equipada com uma caixa de gelo para conservar os peixes por um longo período de tempo em que a pescaria avança.
} 
Sendo assim, barcos forasteiros são sumariamente excluídos do processo de captura do pescado.

Parte da literatura especializada da área afirma que a intensificação da pesca tem aumentado a pressão sobre os estoques pesqueiros (McGRATH et al, 1998) e esse processo tem levado a construção de acordos de pesca (AZEVEDO e APEL, 2004; BATISTA et al, 2004; CERDEIRA, 2009) que visam ordenar que atores sociais podem fazer uso do recurso sem colocar em risco a oferta de pesca e a integração socioeconômica das comunidades que sobrevivem, em parte, da obtenção desses recursos. A constante ameaça de perda de estoques pesqueiros, o risco de comunitários locais desobedecerem às regras instituídas comunalmente e a perda da biodiversidade somam-se ao esforço coletivo na construção desses acordos e à vigilância permanente de sua vigência. Sem dúvida, os conflitos socioambientais na Amazônia brasileira emergem na discussão da esfera pública a partir de catástrofes ambientais em diferentes escalas, onde pequenos produtores rurais dedicados à pesca, agricultura, à caça, à coleta engajam-se para promover ações e políticas na tentativa de preservar e conservar os recursos ambientais indispensáveis à reprodução social desses grupos (ACSELRAD, 2010).

O’Dwyer (2011), ao estudar a produção do território na várzea do Baixo Amazonas, no Pará, relaciona os modos de vida e as condições de reprodução social dos varzeiros, percebidas como atividade pesqueira, agricultura e extrativismo como interface imprescindível na autoatribuição social que estes atores sociais constroem a respeito do território da comunidade ribeirinha e em relação às outras. Dito isto, segue a autora que o reconhecimento social e político dessa modalidade de campesinato serve como instrumento de ordenação e gestão sobre o território historicamente ocupado. A categoria social do reconhecimento está intrinsecamente relacionada à luta que os atores sociais estabelecem para que suas demandas sociais, identitárias e políticas possam ser respeitadas intersubjetivamente. Munido do conceito de reconhecimento social desenvolvido por Honneth (2011), descrito a partir da ideia inicial preconizada por Hegel, o autor reconstrói este conceito a partir da perspectiva de que a base da interação social é o conflito e a reivindicações imanentes a esse processo intersubjetivo é a constante luta por reconhecimento social pelos atores situados na arena pública. Essa luta emergiria, grosso modo, pela busca da autoconservação. 
Nesse sentido lato, os conflitos decorrentes do cenário de desrespeito por parte dos barcos-geleiras que exploram os recursos pesqueiros percebidos como comunitários pelos ribeirinhos do Tapajós impulsiona-os a desenvolver um tipo de luta em busca do reconhecimento social de suas reivindicações e a construção intersubjetiva do respeito à identidade e autonomia sociais. Essa luta, reconhecem os ribeirinhos, perpassa pela construção sistemática de acordos de pesca que normatizem o acesso ao território pesqueiro que, nesse momento, encontra-se sem regras e normas sociais a serem respeitadas e acatadas por todos os atores sociais diretamente envolvidos (stakeholders). Em termos gerais, Honneth apresenta a ideia hegeliana de construir os pressupostos filosóficos para a construção de uma coletividade ética animada pelo estado de natureza hobbesiano, cujo conflito se realiza a partir de uma potência moral entre sujeitos subjetivamente interessados e movidos por uma eticidade.

Diferentemente de Honneth, Olson (1999) propõe uma teoria da ação coletiva a partir da gênese da associação de atores a organizações e grupos sociais específicos para o alcance de objetivos coletivos. Como Olson desenvolve sua teoria da ação coletiva sob a démarche das organizações e suas associações econômicas, o destino social das ações é obter a promoção dos interesses dos seus membros. É nesse ponto que os dois autores se distanciam em suas propostas analíticas e ontológicas da organização subjetiva e objetiva da vida social. Os padrões de reconhecimento intersubjetivo, ainda pensando Honneth as reflexões do primeiro Hegel, articulam-se no sentido de propiciar a reprodução da vida social onde os sujeitos aprendem a conceber as normas como vetor finalístico para seus destinatários sociais; coerção normativa essa que obriga os atores sociais a construir o reconhecimento recíproco, onde "as lutas moralmente motivadas de grupos sociais, sua tentativa coletiva de estabelecer institucional e culturalmente formas ampliadas de reconhecimento recíproco" (HONNETH, 2011: 156), cujo conflito é fundamental na evolução moral da sociedade. Aqui deter-nos-emos em duas categorias-chave para compreender as dinâmicas das lutas dos ribeirinhos: o desrespeito e reconhecimento jurídico.

As formas de desrespeito são, segundo ainda este autor, um equivalente negativo das suas correspondentes relações de reconhecimento (HONNETH, Ibidem). Determinadas formas de rebaixamento e de ofensa agridem a honra e o respeito de determinados 
grupos sociais. Os pescadores artesanais relatam que em muitas ocasiões as disputas entre eles e os membros embarcados dos barcos-geleiras ocasionam em cenários tensos, inclusive na ameaça verbal de agressão física. Os ribeirinhos contam que se sentem continuamente prejudicados e "trapaceados" pelos barcos que vêm de fora e "roubam" o pescado que consideram de propriedade comum das comunidades envolvidas nessas disputas.

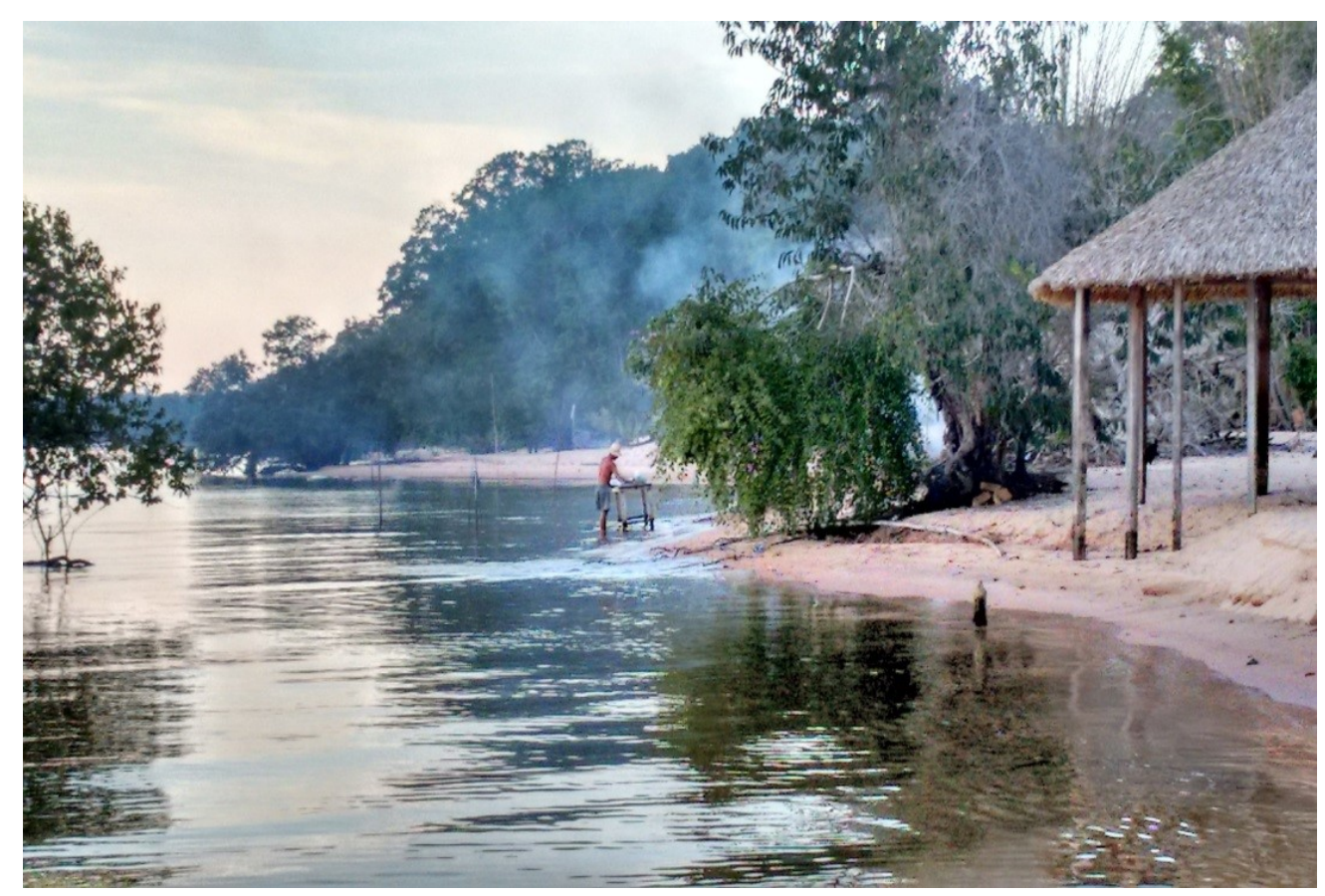

Figura 5. A entrada de barcos-geleiras nos rios e lagos são um problema socioeconômico frequente no cotidiano dos ribeirinhos.

O reconhecimento jurídico se expressa quando sujeitos se respeitam mutuamente, reconhecendo-se como pessoas de direito, direito esse que vai se ampliando numa reconstrução histórica, cuja coletividade e sujeitos envolvidos passam a ser vistos como membros com igual valor da coletividade política, cabendo a eles o direito igual à participação no processo democrático de formação da vontade. A cabo dessas questões, os direitos sociais ampliam-se no campo da filosofia política, uma vez que reconhecer-se reciprocamente como pessoa de direito significa que o sujeito é encontra reconhecimento jurídico não só na capacidade abstrata de poder orientar-se por normas morais, mas inclusive de obter o nível de vida necessário para tal.

Esses direitos só são construídos através da luta social, sua gênese é o conflito. O conflito é a gramática do reconhecimento social, em suas mais diversas gradações 
intersubjetivas e no eixo de relações que a subjetividade se articula. Em certa medida, a proposta analítica de Honneth é evolutiva - não no sentido expressamente positivista - no sentido de que as lutas sociais, na medida em que avançam, transmite direitos a um número crescente de membros da sociedade, palco e cenário dessas disputas. Relatos de pescadores, presentes na reunião do Conselho Consultivo, descrevem que a perda contínua dos estoques de pesca para esses barcos de fora gera uma sensação de incapacidade de lutar pelo direito ao acesso a esses recursos, além de se sentirem desamparados institucionalmente, pois tanto o IBAMA e o IcmBio não tem prerrogativas legais para "patrulhar" as águas do rio, pois este é de acesso livre.

O devir histórico das lutas sociais efetiva-se através dos confrontos práticos, onde os direitos e suas desigualdades são debatidos e ampliados de modo a garantir a inclusão de mais membros na arena do acesso ao reconhecimento social, conferindo o status de pessoa de direito a seus possíveis membros, daí o reconhecimento jurídico tomar corpus através da conquista do autorrespeito. O autorrespeito é um tipo de estima social atrelado precipuamente à honra social, cuja reputação que uma pessoa ou grupo social é capaz de adquirir quando consegue cumprir habitualmente expectativas coletivas (Honneth, 2011). Honneth reconhece, inclusive, os confrontos econômicos pertencem também à luta social pelo reconhecimento atreladas à estima social e reputação dos membros de uma determinada coletividade. Nesse sentido, usamos o termo reforma agrária aquática como a promoção de políticas públicas voltadas para o setor no sentido de garantir, juridicamente, a construção de territórios para manejo dos estoques pesqueiros no sentido de assegurar a reprodução social dessas comunidades ribeirinhas e o acesso à qualidade de vida intersubjetiva, que pode ser pensada como a contínua afirmação de direitos sociais individuais e coletivos, indispensáveis à elaboração subjetiva da estima social.

Para Honneth (Ibidem), a conquista de direitos no mundo moderno, construído e constituído sob estruturas desiguais de acesso a direitos, passa necessariamente no campo das lutas sociais; diferentemente, para Olson (Ibidem), quando um certo número de indivíduos tem um interesse comum ou coletivo, compartilhando propósitos ou objetivos, quando a ação individual não alcançou o sucesso na tentativa da satisfação da busca desse "interesse" - daí a necessidade de mobilizar-se via instituições e organi- 
zações. Acreditamos que a contribuição heurística dos dois autores trata de questões semelhantes - a ação social de atores sociais motivados em busca de alcançar objetivos coletivos - eles problematizam nuances diversas: Olson pensa a ação coletiva no nível das organizações e meios eficazes para as satisfação de grupos sociais e suas dinâmicas finalísticas; Honneth argumenta a partir das reflexões de Hegel a respeito da categoria do reconhecimento, como o conflito social só pode ser "administrado" através de múltiplas dimensões da intersubjetividade, através do reconhecimento da eficácia do aparelhamento jurídico, da família e dos laços de solidariedade na observância e cumprimento da universalização dos direitos e na promoção da estima social, autoproteção e autorrespeito dos membros envolvidos nas referidas disputas sociais.

\section{Considerações finais}

Há uma extensa literatura sobre a questão fundiária no Brasil e a dificuldade de acesso à terra por parte dos setores historicamente marginalizados no processo de produção de riqueza econômica (ABRAMOVAY, 1992; MARTINS, 2000; MEDEIROS, 1989; HOUTZAGER, 2004). Em paralelo a isso, nas últimas décadas constituiu-se, sob a observação e vigilância da Constituição Federal de 1988, a proteção dos territórios indígenas e quilombolas, ressalvadas as suas especificidades jurídicas. A ambientalização das lutas sociais, segundo Acselrad (2010) compreende o processo de adoção de um discurso ambiental por parte de diferentes grupos sociais com a incorporação de justificativas ecológicas para legitimar não apenas as lutas e reivindicações desses grupos, mas operam, inclusive, na busca de práticas institucionais consoantes a essas demandas e imperativos políticos para a justiça ambiental, demandas estas definidas por Teisserenc (2014) como "cuidado ambiental".

Os corpos d'água integravam o conjunto jurídico da organização territorial desses grupos sociais, no entanto, nas últimas décadas, como vimos, populações tradicionais ribeirinhas começaram a ser mobilizar politicamente para ter a propriedade comum dos territórios aquáticos, o acesso e uso dos recursos naturais existentes nos complexos ecossistemas lacustres na Amazônia (BENATTI, 2011). Dadas às conquistas, em meio também a projetos que ruíram por conta de características socioculturais historicamente delineadas no tempo em curso dessas implantações de acordos, sobejamente sob o au- 
xílio de projetos como lara e PróVárzea, ocorreu um fenômeno social relevante do ponto de vista socioeconômico que foi o delineamento de uma reforma agrária aquática, onde os territórios aquáticos cultural e historicamente apropriados, foram se transformando em propriedades de uso comum e possibilitando meios capazes de contribuir para a reprodução social das populações ribeirinhas protagonistas na construção dessas normas e regras socialmente construídas.

Reapropriando-se das ideias de Benatti (Ibidem), acreditamos que o manejo comunitário dos territórios aquáticos, compartilhando os estoques pesqueiros presentes no lago local, possibilita aos ribeirinhos do Tapajós resolver os conflitos sociais referentes ao acesso e uso dos recursos aquáticos, fixando-os nos lugares de origem; cria alternativas econômicas e, por fim, assegura espaço "físico" para a produção de uma cultura ribeirinha alicerçada nos saberes tradicionais construídos com o contato com o rio, os peixes, o vento, regime de alternância das estações. Além do mais, viabiliza a promoção da justiça social e a sustentabilidade ambiental, pois aumenta a autonomia econômica e reduz os impactos sociais sobre os ecossistemas lacustre e fluvial, pois "o uso prolongado e a convicção de que a observância da norma costumeira corresponde a uma necessidade jurídica" (ALVES, 1996). Trata-se, pois, como defende Sawyer (2011), numa importante política local para o estabelecimento do uso sustentável da biodiversidade como estratégia ecossocial, criando-se territórios socioambientais sob a tutela legítima das comunidades ribeirinhas.

Pereira (2009) tratar do papel de Santarém como pólo catalisador de intensas dinâmicas sociais e políticas na região, descreve que as dinâmicas econômicas, políticas e dos decorrentes conflitos socioambientais envolvem, via de regra, diferentes segmentos e atores sociais em redes sociopolíticas; o mesmo autor afirma que ao pensar as cidades amazônicas como palco de disputas de territórios, esses confrontos podem implicar em processos complexos de alianças, confrontos, rupturas, adesões e ameaças de morte e assassinatos. Em termos dessas disputas em sociedades ribeirinhas, convém frisar que houve a conhecida Guerra do Peixe, no Estado do Amazonas, nos anos 70, onde diversos atores sociais deflagraram um conflito em torno do controle da posse dos lagos Janauacá e que redundou em morte, agressões físicas e na instabilidade social e política da região (McGRATH et al., 1991). 
Percebemos que o protagonismo histórico dos ribeirinhos do Tapajós é um continuum das lutas sociais empreendidas pelos ribeirinhos da várzea santarena e que são resultado de complexos processos de construção identitária e de intensa relação com os espaços naturais (HALWASS, 2015), percebendo-os numa mediação social que vai além da satisfação das necessidades sociais de reprodução. Sugerimos, inclusive, que as necessidades sociais coincidem com necessidades culturais e ecológicas. É necessário frisar que as ações politicamente engajadas dos ribeirinhos são orientadas pelo escopo moral das interações dentro dos grupos sociais e em relação às mediações via instituições públicas. Sem dúvida, a luta por reconhecimento, segundo Honneth (2011), como uma força moral, promove desenvolvimento e progresso na realidade da vida social em grupos que historicamente percebiam-se num cenário de injustiça e desigualdade jurídica (CAMARGO, 2006). Essa força moral junge-se aos conflitos sociais sob as crescentes exigências do reconhecimento e Honneth a correlaciona à promoção da vida boa, intrinsecamente ligada à eticidade. É importante frisar, contudo, que a produção de conhecimento crítico, conforme aponta Pereira (2009) pode fornecer subsídios para a mobilização política popular, a construção de políticas públicas democráticas que atendam às demandas socioculturais dessas comunidades ribeirinhas, numa arena de debate e proposição de jurisdição especificas, gerando novos sentidos e contextos para as relações entre governo e sociedade.

\section{Consideração complementar}

Os ribeirinhos da Flona do Tapajós e a Reserva Extrativista Tapajós-Arapiuns conquistaram, após longas décadas de lutas sociais, a implementação de acordos de pesca que cobrem 57 comunidades dessas unidades de conservação. Encontra-se em Brasília o processo número 0212100064/2017-70 que institui esse acordo, que cobre de Suruacá até Escrivão, na margem esquerda e, na margem direita, São Domingos e Aveiro. Segundo a Minuta do IcmBio (2017), comunidades da bacia do Tapajós de duas unidades de conservação, incluindo a reserva extrativista Arapiuns e a Floresta Nacional do Tajapós, contarão a partir do ano de 2017 com um acordo de pesca que aumenta a preservação dos peixes e, por consequência, da biodiversidade local. Construído ao longo dos últimos 10 meses, o acordo irá normatizar a pesca na região, com regras para a 
quantidade de peixes e ferramentas permitidas, por exemplo, além de prever campanhas de educação ambiental e um sistema de monitoramento que irá analisar os impactos nos estoques pesqueiros e a eficiência do acordo pelos próximos 3 anos. O sistema será desenvolvido pelo Instituto de Pesquisa Ambiental da Amazônia - IPAM em parceria com a Universidade Federal do Oeste do Pará e o ICMBio.

"Esse acordo é muito importante porque a complexa região do Tapajós, cortada por UC's e terras indígenas, tem uma pressão de pesca ilegal muito grande. Colocar todos os agentes para debater esse contexto foi fundamental", afirma Alcilene Cardoso, coordenadora do escritório do IPAM em Santarém.

O sistema precisará de 6 a 8 meses para diagnósticos iniciais. Nos últimos 10 meses foram consultadas todas as comunidades envolvidas que participaram da elaboração dos documentos e da capacitação de lideranças comunitárias extrativistas e indígenas. A construção do acordo envolveu um grupo de trabalho formado pelo Conselho Indígena do Tajapós, Organização Tapajoara, colônias de pescadores dos municípios de Santarém e Belterra, IBAMA, IcmBio, IPAM, UFOPA e comunidades.

O processo que institui o Acordo de Pesca encontra-se em Brasília, no Ministério do Meio Ambiente, aguardando homologação e publicação no Diário Oficial da União.

\section{Agradecimentos}

Agradeço à contribuição de Andrew Matheus Fernandes Salgado, bolsista PIBIC/PROPPIT da Universidade Federal do Oeste do Pará. Agradeço, ainda, às contribuições e sugestões da leitura atenta e generosa dos originais por parte dos colegas Roberth Rodrigues Ferreira, Fábio Gomes de França e Antonio Francisco Perrone Oviedo. Ao apoio técnico do pessoal do IcMBio.

\section{Referências}

ABRAMOVAY, Ricardo. Paradigmas do capitalismo agrário em questão. São Paulo - Rio de Janeiro - Campinas: Editora Hucitec - ANPOCS - Editora da Unicamp, 1992.

ACSELRAD, Henri. Ambientalização das lutas sociais - o caso do movimento por justiça ambiental. Estudos Avançados, 24 (68), 2010, p. 103 - 119. Acesso em 20 de novembro de 2017. DOI: http://dx.doi.org/10.1590/S0103-40142010000100010 
ALMEIDA, Alfredo Berno Wagner de. Prólogo: um rio dividido? In: Alfredo Berno Wagner de (org.). Mobilizações étnicas e transformações sociais no Rio Negro. Manaus; EDUA, 2010, p. 7 - 20.

ALVES, José Carlos M. O direito consuetudinário. Notícias do Direito Brasileiro. Brasília: Unb, 1996, p. 15 - 37.

AZEVEDO, Cleidimar Ribeiro de e APEL, Marcelo. Co-gestão: Um processo em construção na várzea amazônica. Manaus: ProVárzea/IBAMA, 2004.

BATISTA, V. da S. ISAAC, V.; VIANA, J. P. Exploração e manejo dos recursos pesqueiros na Amazônia. In: RUFFINO, Mauro Luís. A pesca e os recursos pesqueiros na Amazônia brasileira (Org.). Provárzea/IBAMA, 2004. p. 63 - 151.

BENATTI, José Heder. Propriedade comum na Amazônia: acesso e uso dos recursos naturais pelas populações tradicionais. In: SAUER, Sérgio; ALMEIDA, Wellington. Terras e territórios na Amazônia: demandas, desafios e perspectivas. Brasília: EdUnB; Abaré Editorial, 2011, p. 93 - 113.

CAMARGO, Silvio. Axel Honneth e o legado da Teoria Crítica. Programa de PósGraduação em Sociologia - UFPB. Política \& Trabalho: Revista de Ciências Sociais, Número 24, Abril de 2006, p. 123 - 138.

CASTRO, Edna. Território, biodiversidade e saberes de populações tradicionais. In: , Antonio Carlos (org.). Etnoconservação: novos rumos para a proteção da natureza nos trópicos. São Paulo: HUCITEC, 2000, p. 165 - 182.

CERDEIRA, Regina Glória Pinheiro. Acordo de Pesca como instrumento de Gestão Participativa na Amazônia. Dissertação de Mestrado (Mestrado em Direito Ambiental). Universidade do Estado do Amazonas, 2009.

DIEGUES, Antonio Carlos. Repensando e recriando as formas de apropriação comum dos espaços e recursos naturais. In: DIEGUES, Antonio Carlos e MOREIRA, André de Castro C. Espaços e recursos naturais de uso comum. São Paulo: NUPAUB, 2001, p. 97 $-124$.

ESPINHEIRA, Gey. Metodologia e prática do trabalho em comunidade. Salvador: EDUFBA, 2008.

ESTERCI, Neide. Cientistas e povos da floresta: a invenção de novos territórios de proteção ambiental na Amazônia. In: ESTERCI, Neide; SANTANNA jr, Horácio Antunes de;

TEISSERENC, Maria José Aquino (org). Territórios socioambientais em construção na Amazônia brasileira. Rio de Janeiro: 7 Letras, 2014, p. 21 - 38.

FERREIRA, Roberth Rodrigues. Gênero de vida e recursos de uso comum: um estudo da comunidade Ilha de São Miguel - Santarém, Pará. Trabalho de Conclusão de Curso - Licenciatura Plena em Geografia / Universidade Federal do Oeste do Pará. Santarém, ICED / UFOPA, 2014, 95p.

GODELIER, Maurice. Antropologia. São Paulo: Ática, 1981.

HALLWASS, Gustavo. Etnoecologia e Pesca: influência de Unidades de Conservação e aplicação do Conhecimento Ecológico Local de pescadores no ma- 
nejo e conservação dos recursos pesqueiros no Baixo Rio Tapajós, Amazônia Brasileira. Programa de Pós-Graduação em Ecologia - Universidade Federal do Rio Grande do Sul (Tese de Doutorado). Porto Alegre, Março de 2015, 178 páginas. Acesso em 20 de outubro de 2017. Link para acesso: https://www.lume.ufrgs.br/bitstream/handle/10183/119625/000969840.pdf

HARTMANN, Wolf D. Conflitos de pesca em águas interiores da Amazônia e tentativas para sua solução. In: DIEGUES, Antonio Carlos e MOREIRA, André de Castro C. Espaços e recursos naturais de uso comum. São Paulo: NUPAUB, 2001, p. 123 - 138.

HONNETH, Axel. Luta por reconhecimento: a gramática moral dos conflitos sociais. São Paulo: Editora 34, 2011.

MARTINS, José de Souza. Reforma agrária - o impossível diálogo. São Paulo: Edusp, 2000.

McGRATH, David. CASTRO, Fábio. CÂMARA, Evandro. FUTEMMA, Célia. Manejo comunitário de lagos de várzea e o desenvolvimento sustentável da pesca na Amazônia. Novos Cadernos NAEA. Belém, v. 1, n. 2, 1998. Acesso em 10 de outubro de 2017. DOI: http://dx.doi.org/10.5801/ncn.v1i2.4

McGRATH, D. G. CALABRIA, Juliana. AMARAL, Benedito. FUTEMMA, Célia. CASTRO, Fábio. Varzeiros, geleiros e o manejo dos recursos naturais na várzea do Baixo Amazonas. Papers do NAEA. Belém: 1991.

MEDEIROS, Leonilde S. de. História dos movimentos sociais no campo. Rio de Janeiro: FASE, 1989.

MENEZES, Elieyd Sousa de. Conflitos socioambientais e transformações sociais em Novo Airão. In: ALMEIDA, Alfredo Berno Wagner de (org.). Mobilizações étnicas e transformações sociais no Rio Negro. Manaus; EDUA, 2010, p. 375 - 394.

MINISTÉRIO DO MEIO AMBIENTE. Relatório Parametrizado - Unidade de Conservação: Reserva Extrativista Tapajós-Arapiuns. Link para acesso: http://sistemas.mma.gov.br/cnuc/index.php?ido=relatorioparametrizado.exibeRelatorio \&relatorioPadrao $=$ true \&idUc $=259$

MINISTÉRIO DO MEIO AMBIENTE. Relatório Parametrizado - Unidade de Conservação: Floresta Nacional do Tapajós. Link para acesso: http://sistemas.mma.gov.br/cnuc/index.php?ido=relatorioparametrizado.exibeRelatorio \&relatorioPadrao $=$ true\&idUc $=123$

O'DWYER, Eliane Cantarino. A produção do território na várzea no Baixo Amazonas. In: SAUER, Sérgio; ALMEIDA, Wellington. Terras e territórios na Amazônia: demandas, desafios e perspectivas. Brasília: EdUnB; Abaré Editorial, 2011, p. 239 - 255.

OLSON, Mancur. A lógica da ação coletiva. São Paulo: EDUSP, 1999.

OVIEDO, Francisco Perrone. BURSZTYN, Marcel. DRUMMOND, José Augusto. Agora sob nova administração: acordos de pesca nas várzeas da Amazônia brasileira. Ambiente \& Sociedade. São Paulo, v. XVIII, n. 4, p. 119 -138, 2015. Acesso em 10 de outubro de 2017. DOI: http://dx.doi.org/10.1590/1809-4422ASOC985V1842015

PEREIRA, José Carlos Matos. O papel de Santarém como cidade média na Amazônia 
Oriental. In: CASTRO, Edna (org.). Cidades na floresta. São Paulo: Annablume, 2009, p. 329 - 352.

PERROTA, Ana Paula. Emergência de noções e práticas ambientalistas ribeirinhas face à pesca artesanal. In: ESTERCI, Neide; SANTANNA jr, Horácio Antunes de; TEISSERENC, Maria José Aquino (org). Territórios socioambientais em construção na Amazônia brasileira. Rio de Janeiro: 7 Letras, 2014, p. 137 - 168.

RUFFINO, Mauro Luís. Gestão do uso dos recursos pesqueiros na Amazônia. Manaus: IBAMA, 2005.

SAWYER, Donald. Unidades de Conservação, uso sustentável e funções socioecossistêmicas na Amazônia e no Brasil. In: SAUER, Sérgio; ALMEIDA, Wellington. Terras e territórios na Amazônia: demandas, desafios e perspectivas. Brasília: EdUnB; Abaré Editorial, 2011, p. 363 - 380.

SILVA, Rubens Elias da; SOUZA, Rogério Ribeiro de; BONFIM, Fernanda da Silva. A extração do látex e a coleta de sementes em comunidades da FLONA do Tapajós: bases empíricas para a discussão da racionalidade ambiental. Revista Gaia Scientia. João Pessoa. Vol. 10, Número 1, 2016, p.126 - 132 . DOI: http://dx.doi.org/10.21707/gs.v10.n01a14

Rubens Elias da; SALGADO, Andrew Matheus Fernandes. Gestão social das águas na FLONA e Reserva Extrativista do Tapajós-Arapiuns: estudo socioantropológico sobre os conflitos para demarcação de zonas de pesca e mobilização social para a gestão e preservação dos territórios de pesca comunitária. Relatório Final do Projeto de Iniciação Científica (PROPPIT / Universidade Federal do Oeste do Pará), 2016.

Rubens Elias da; FERREIRA, Roberth Rodrigues. Construção de Acordos de Pesca e Políticas Públicas para gestão de recursos pesqueiros na Região de Santarém, Pará (1990 - 2004). Artigo original. 24 p.

SOARES, Eduardo Safons. "A Floresta Nacional do Tapajós": desafios, resultados, ameaças, e oportunidade em uma Unidade de Conservação na Amazônia. Belterra, Pará: IBAMA/Promanejo, 2004.

TEISSERENC, Maria José de Aquino. Atores não governamentais, relações, representações e desafios do desenvolvimento sustentável (na Amazônia brasileira). In: ESTERCl, Neide; SANTANNA jr, Horácio Antunes de; TEISSERENC, Maria José Aquino (org). Territórios socioambientais em construção na Amazônia brasileira. Rio de Janeiro: 7 Letras, 2014, p. 73 - 104. 